\title{
Future Treatment of Constipation-associated Disorders: Role of Relamorelin and Other Ghrelin Receptor Agonists
}

\author{
Paula Mosińska, ${ }^{1 *}$ Hubert Zatorski, ${ }^{1}$ Martin Storr, ${ }^{2}$ and Jakub Fichna ${ }^{1}$ \\ ${ }^{I}$ Department of Biochemistry, Faculty of Medicine, Medical University of Lodz, Lodz, Poland; and ${ }^{2}$ Center of Endoscopy, Starnberg, Germany \\ and Walter-Brendel-Centre, Ludwig-Maximilians University Munich, Munich, Germany
}

There is an unmet need for effective pharmacological therapies for constipation, a symptom that significantly deteriorates patients' quality of life and impacts health care. Ghrelin is an endogenous ligand for the growth hormone secretagogue receptor and has been shown to exert prokinetic effects on gastrointestinal $(\mathrm{Gl})$ motility via the vagus and pelvic nerves. The pharmacological potential of ghrelin is hampered by its short half-life. Ghrelin receptor (GRLN-R) agonists with enhanced pharmacokinetics were thus developed. Centrally penetrant GRLN-R agonists stimulate defecation and improve impaired lower GI transit in animals and humans. This review summarizes the current knowledge on relamorelin, a potent ghrelin mimetic, and other GRLN-R analogs which are in preclinical or clinical stages of development for the management of disorders with underlying Gl hypomotility, like constipation.

(J Neurogastroenterol Motil 2017;23:171-179)

\section{Key Words}

Constipation; Gastrointestinal motility; Ghrelin; Receptors, ghrelin; Relamorelin

\section{Introduction}

Constipation as a chronic digestive condition significantly deteriorates patients' quality of life. It is much more common amongst women compared to men and the probability of the occurrence of constipation increases with age. The worldwide prevalence rates of physician-confirmed or patient self-reported constipation ranges from $12.3 \%$ to $25.1 \% .^{1-5}$ In clinical practice the separation between chronic idiopathic constipation (chronic constipation [CC] of undefined pathophysiology that does not have any organic or physiological cause), constipation-predominant irritable bowel syn- drome (IBS-C), and CC (gastrointestinal [GI] disorder caused by normal colon transit, slow colon transit or dyssynergic defecation) is still difficult. ${ }^{6}$ Although the diagnosis of IBS-C is based on the Rome IV criteria, the diagnosis of CC is made by exclusion of other conditions without thorough investigation. The Bristol stool scale serves as an universal tool for the determination of stool consistency. Regardless of the final diagnosis, each condition is characterized by feeble or absent colonic propagated activity. A great number of drugs tested in preclinical in vivo studies for the treatment of IBS$\mathrm{C}$ are simultaneously verified also as a potential option for $\mathrm{CC}$ or chronic idiopathic constipation. Currently, conventional treatment options used to improve constipation-related symptoms like ab-

Received: October 26, 2016 Revised: December 19, 2016 Accepted: January 8, 2017

(5) This is an Open Access article distributed under the terms of the Creative Commons Attribution Non-Commercial License (http://creativecommons. org/licenses/by-nc/4.0) which permits unrestricted non-commercial use, distribution, and reproduction in any medium, provided the original work is properly cited.

${ }^{*}$ Correspondence: Paula Mosińska, MSc

Department of Biochemistry, Faculty of Medicine, Medical University of Lodz, Mazowiecka, 6/8, 92-215 Lodz, Poland Tel: +48-42-272-5707, Fax: +48-42-272-5694, E-mail: paula.mosinska@umed.lodz.pl 
dominal pain, straining, and hard stools, are of limited efficacy and usually judged as unsatisfactory. ${ }^{7,8}$

Ghrelin is a 28-amino acid peptide produced mainly in the $\mathrm{P} /$ D1 and X/A-like cells of the oxyntic mucosa of the stomach and in the hypothalamus. Importantly, the X/A-like endocrine cells are solely responsible for $80-90 \%$ secretion of ghrelin. The peptide has recently been described as a natural ligand for the ghrelin receptor (GRLN-R), also known as the growth hormone secretagogue$1 \alpha$ receptor. GRLN-Rs are expressed in the central nervous system and in peripheral tissues and are involved in numerous functions $^{9-17}$; the main central and peripheral functions are summarized in Figure. The activation of GRLN-R modulates multiple intracellular signaling pathways and exhibits different endocrine and non-endocrine effects. ${ }^{18}$ While administered either peripherally or centrally, ghrelin stimulates food intake through GRLN-Rs on vagal afferents or via the bloodstream. ${ }^{15,19}$ Moreover, by targeting hypothalamic neurons and the sympathetic nervous system, ghrelin regulates lipid-metabolizing enzymes in adipocytes. ${ }^{20}$ Ghrelin also interacts with the reproductive, cardiovascular and immune sys- tems. ${ }^{21-25}$ Currently, ghrelin is considered as a possible option for the treatment of conditions with impaired gastric motility, reduced GI motility and altered energy balance.

Since the discovery of ghrelin in $1999,{ }^{26}$ its usefulness was thoroughly evaluated in the treatment of upper GI diseases, especially gastroparesis. More recent studies in animals and humans report a prokinetic activity in the lower GI-tract with ghrelin potentially being helpful for the treatment of lower GI diseases, such as CC or postoperative ileus (POI). ${ }^{27,28}$ Although the expression of ghrelin is relatively low in the small and large intestines, when compared to the stomach, the GRLN-Rs are in turn dispersed throughout the GI tract and a high mRNA expression was reported especially in the colon of humans and rodents. In more detail this high expression was reported on fibers and cell bodies of the enteric nervous system in rats, and in the myenteric neurons of the guinea pig ileum. $^{20,29,30}$

Numerous studies in rodents demonstrate an enhanced motor activity in the duodenum following administration of exogenous ghrelin in the fed or fasted state. ${ }^{31-33}$ Moreover, the activation of

\begin{tabular}{|c|c|}
\hline \multicolumn{2}{|c|}{ Central nervous system } \\
\hline $\begin{array}{l}\text { Hypothalamus } \\
\text { - Regulates sleep-wake cycle and } \\
\text { feeding/energy status } \\
\text { - Improves spatial memory performance }\end{array}$ & $\begin{array}{l}\text { Ventral tegmental area } \\
\text { - Regulates reward-related behaviours eg, sucrose } \\
\text { preference, responses to cocaine, alcohol }\end{array}$ \\
\hline $\begin{array}{l}\text { Pituitary gland } \\
\text { - Regulates growth hormon secretion }\end{array}$ & $\begin{array}{l}\text { Other areas } \\
\text { - Stimulates neurogenesis (synaptic plasticity and } \\
\text { synaptogenesis) via dorsal motor nucleus of the } \\
\text { vagus } \\
\text { - Modulates cognitive function }\end{array}$ \\
\hline
\end{tabular}

Liver energy metabolism
- Regulates fatty acid oxidation,
insulin sensitivity, glucose
metabolism
- Regulates the balance between
adipogenesis and lipolysis

\begin{tabular}{|l|}
\multicolumn{2}{|c|}{ Gastric functions } \\
- Enhances gastric \\
emptying \\
- Exhibits gastric \\
protection (anti- \\
inflammatory action) \\
- Regulates acid secretion
\end{tabular}

Cardiovascular functions

- Increases cardiac output - Increases vasodilation - Decreases apoptosis of cardiomiocytes in vitro

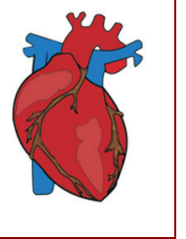

Figure. The effects of ghrelin in various organs. 
GRLN-Rs by centrally penetrant GRLN-R agonists in the lumbosacral spinal cord initiates and enhances propulsive contractile activity in the distal colon. 33,34

Ghrelin induces contractile activity in the GI tract, but the short half-life and plasma instability of ghrelin impairs the usefulness. ${ }^{35}$ Hence, small molecule-GRLN-R agonists with prolonged receptor activity currently represent an attractive therapeutic option for the management of lower GI tract motility disorders. In this review we summarize the latest preclinical and clinical studies evaluating the potential of relamorelin and other GRLN-R agonists in improving delayed colonic transit.

\section{Relamorelin}

Relamorelin (RM-131) is a pentapeptide synthetic ghrelin analog that stimulates the release of growth hormone in a comparable manner as natural ghrelin. It binds to the GRLN-R with approximately 3 -fold higher affinity to ghrelin receptors than native ghrelin. ${ }^{36,37}$ Moreover, RM-131 exerts improved stability, greater potency, and longer plasma half-life. ${ }^{36,38} \mathrm{RM}-131$ may be used in the treatment of gastroparesis, since in gastroparesis RM-131 accelerates gastric emptying without causing severe adverse effects. The most common side effects in RM-131 treated patients are dizziness, fatigue, abdominal pain/cramping, hunger, feeling cold, and muscular weakness. ${ }^{39}$ Considering the prokinetic properties of RM-131 on the upper GI tract, many studies put also an interest on its effect in the treatment of the lower GI motility disorders. A study by Van der Ploeg et $\mathrm{al}^{36}$ showed that RM-131 reversed the reduction of gastric emptying and was up to 100 -fold more potent than ghrelin or other ghrelin mimetics in rat models of POI and morphine-induced ileus. Besides its effect on gastric emptying, oral administration of RM-131 also enhanced GI transit in the proximal and middle part of the small intestine. Moreover, in a rat model of TNBS-induced GI inflammation the administration of a single dose of RM-131 (5 or $50 \mathrm{nmol} /$ mouse) increased the rats' survival and reduced signs of macroscopic colonic inflammation, suggesting that RM-131 also mediates an anti-inflammatory response. ${ }^{36}$

Translated into humans, in a randomized, double-blinded, placebo-controlled trial, RM-131 administered subcutaneously for 14 days at the dose of $100 \mu \mathrm{g} /$ day significantly reduced the symptoms of constipation in females with CC who met the Rome III criteria. ${ }^{37}$ RM-131 significantly enhanced bowel function by increasing the number of spontaneous bowel movements and accelerated GI and colonic transit. Importantly, the positive response was observed immediately after the first administration of RM-131. The primary clinical endpoint for the function of the intestine was stool consistency (assessment based on the Bristol stool scale), and the secondary endpoints included stool frequency, time to first bowel movement and completeness of evacuation. The ghrelin agonist was welltolerated. Some patients experienced tiredness, enhanced appetite and headache.

More recently, Acosta et $\mathrm{al}^{40}$ characterized the acute motor effects of RM-131 in patients with CC using colonic barostat and multilumen manometry. In a placebo-controlled, single dose, double blind, randomized study Acosta et $\mathrm{al}^{41}$ showed that a subcutaneous injection of isotonic RM-131 solution significantly increased colonic propagated contractions (PCs) and in consequence accelerated overall colonic motor activity. No differences in the number of high amplitude propagated contractions (HAPCs) and in sensation thresholds for gas and pain were observed between the RM-131-treated and control groups. However, the administration of RM-131 resulted in an increased frequency of pre-meal PCs and a significantly higher number of postprandial PCs, when compared to the placebo group. The observed activity in the colon is comparable to the effects seen following a treatment with other colonic prokinetics such as prucalopride, or other serotonin receptor agonists or neostigmine; however, in contrast to the above mentioned drugs RM-131 exhibits a delayed effect (24-36 hour postadministration) on the colonic motility. ${ }^{42-44}$ To further characterize the effects reported in the human colon the same group of authors evaluated the clinical efficacy of RM-131 in patients with confirmed CC. Similarly to their first clinical trial, the propulsive effects of RM-131 were confirmed, and the trial added that the duration of RM-131 is long-lasting with RM-131 activity being reported for a minimum of 1 hour. $^{41}$

Another study interested in the underlying mechanisms demonstrated that RM-131 hyperpolarizes the resting membrane potential of mouse and human colon circular smooth muscle cells and decreases colonic intraluminal pressure. ${ }^{45}$ RM-131 exerted no effect on either fast inhibitory junction potentials or slow inhibitory junction potentials. The concurrent effect of RM-131 in decreasing colonic intraluminal pressure and increasing upper GI contractility may widen its application towards functional GI disorders. ${ }^{46}$

Very recently, a single-center, placebo-controlled, double-blinded study was initiated in patients with $\mathrm{CC}$ who received a single injection of $100 \mu \mathrm{g}$ of RM-131. The primary endpoint included the effect of RM-131 on postprandial HAPC within one hour. No results have been published yet; however, the trial may be followed under the Clinical Trial registration number (ClinicalTrals gov. Identifier: NCT 02137642). 


\section{Other Ghrelin Receptor Agonists}

The defecation center in the lumbo-sacral spinal cord constitutes an investigational target for the treatment of constipation. Small-molecules, such as urimorelin, capromorelin, EX-1314, CP464709, GSK894281, and ipamorelin stimulate this center and are thought to ameliorate bowel movement in animals. A small number of clinical trials have been performed so far (Table 1).

\section{Ulimorelin (TZP-101)}

Ulimorelin is a macrocyclic peptidomimetic agent widely investigated in the management of diabetic gastroparesis (ClinicalTrials. gov Identifier: NCT00612014) and POI (ClinicalTrials.gov Identifier: NCT01710982) but more recently it is also in the spotlight in the treatment of constipation. Pustovit et $\mathrm{al}^{47}$ reported a dose-dependent increase in the numbers and amplitudes of phasic pressure waves in the colorectum in anesthetized rats following intravenous administration of ulimorelin. Interestingly, when delivered directly to the lumbo-sacral spinal cord, ulimorelin increased propulsive activity more significantly compared to intravenous injections. The effect of ulimorelin was blocked by both the nicotinic receptor antagonist (hexamethonium) and GRLN-R antagonist, indicating that the responses were dependent on sustained activation of neuronal pathways. Yet, there are no clinical trials evaluating the effect of this GRLN-R agonist in patients with constipation.

\section{Capromorelin}

In a rat model of low fiber-induced constipation, capromorelin stimulates colonic motility and improves defecation patterns. ${ }^{48}$

Ferens et $\mathrm{al}^{34}$ reported that when applied intravenously at a dose of $4 \mathrm{mg} / \mathrm{kg}$, capromorelin elicits contractions in the colon of spinal cord-injured rats resulting in spontaneous defecations. Though, the safety profile, tolerability and pharmacokinetic properties of capromorelin was assessed in spinal cord-injured patients with constipation, ${ }^{49}$ the currently available data is not detailed enough to support a possible clinical application of capromorelin in the management of constipation. There are no ongoing studies registered in ClinicalTrials.gov, suggesting that its development may no longer being pursued.

\section{EX-1314}

Oral administration of the small-molecule EX-1314 (Elixir) at a dose of $300 \mathrm{mg} / \mathrm{kg}$ significantly enhanced small intestinal transit in mice, when compared to vehicle-treated controls. ${ }^{50}$ The administration of EX-1314 in fed animals resulted in a 2-fold greater fecal output compared to the control group. In contrast, in fasted animals EX-1314 did not show significant differences in fecal pellet outputs. Thus a stimulation of food intake by the synthetic GRLN-R agonist may be needed to facilitate the prokinetic effects of GRLN$\mathrm{R}$ agonists. None of the groups showed signs of diarrhea or other side effects.

GRLN-R has prokinetic effects on morphine-induced hypo-

Table 1. Ghrelin Receptor Agonists Under Investigation in Preclinical Animal Studies

\begin{tabular}{|c|c|c|c|c|}
\hline Generic name & $\begin{array}{c}\text { Route of } \\
\text { administration }\end{array}$ & Effect & Animal model & Reference No. \\
\hline Capromorelin & iv, po & $\begin{array}{l}\text { Similar observations in stimulating colorectal } \\
\text { propulsion observed in treated and control } \\
\text { group }\end{array}$ & Diet-induced constipation & 48 \\
\hline CP464709 & iv, intrathecal & $\begin{array}{l}\text { Increased fecal pellet output; stimulation of } \\
\text { defecation }\end{array}$ & Control rats & 33 \\
\hline GSK894281 & po & Dose-related increase in fecal pellet output & Control rats & 47 \\
\hline EX-1314 (Elixir) & po & Increased SIT & $\begin{array}{l}\text { Mice with opioid-induced ileus; } \\
\text { opiate-induced GI dysmotility }\end{array}$ & 50 \\
\hline Ipamorelin & iv & Increases cumulative fecal pellet output & Rats with POI & 51 \\
\hline \multirow[t]{3}{*}{ TZP-101 (Ulimorelin) } & iv & Increased colonic transit and fecal pellet output & Rats with POI & 28 \\
\hline & iv & $\begin{array}{l}\text { Increased the colorectal propulsive activity and } \\
\text { fecal pellet output }\end{array}$ & Control rats & 49 \\
\hline & iv & Increased gastric emptying and SIT & $\begin{array}{l}\text { Rats with POI; rats with } \\
\text { morphine-induced dysmotility }\end{array}$ & 36 \\
\hline
\end{tabular}

iv, intravenous; po, per os; SIT, increased small intestinal transit; GI, gastrointestinal; POI, postoperative ileus. 
motility. EX-1314 reversed the action of morphine and restored the small GI transit in mice to levels observed for controls. ${ }^{50}$

\section{CP464709}

CP46709 is centrally penetrant following subcutaneous or intravenous application and improves colonic motility and defecation patterns in rats. ${ }^{33,52}$ When injected subcutaneously at a dose of 5 or $10 \mathrm{mg} / \mathrm{kg}, \mathrm{CP} 464709$ caused a substantial stimulation of defecation in the first hour following administration, which represented fourfold increased defecation rates compared to vehicle-treated animals. This effect diminished at greater doses ( $>20 \mathrm{mg} / \mathrm{kg}$ ) suggesting a possible dose-dependent desensitization of receptors. ${ }^{33,52}$

Consistently, rats injected with CP46470 intravenously demonstrated strong propulsive contractions in the colorectum, without changing the baseline motility of the colon. It is thus possible that the GRLN-R agonist activates the defecation center of the L6S2 lumbo-sacral region of the spinal cord, stimulating autonomic nerve input and thus promoting colorectal motility, without direct effects on colonic smooth muscle cells. ${ }^{33,52}$ This effect was observed in conscious as well as in anesthetized rats, and was manifested by a substantial stimulation of defecation without affecting small intestinal motility.

\section{GSK894281}

GSK894281 is another small-molecule that when administered orally to rats enhanced the fecal output nearly four times, compared to controls. ${ }^{46}$ The pharmacokinetic evaluation of GSK894281 showed high potency towards GRLN-Rs, with a half-life up to 5.5 hours, and a bioavailability of $75 \%$ following oral administration. ${ }^{46}$ The peak of fecal expulsion was observed during the first 30 minutes after GSK894281 administration $(10 \mathrm{mg} / \mathrm{kg})$ suggesting a very fast onset of action. There is no loss of action since even after chronic administration for 8 consecutive days (daily dose of $10 \mathrm{mg} /$ $\mathrm{kg}$ ), GSK894281 maintained a powerful prokinetic effect. The fecal output was approximately $16 \%$ greater until the 6 th control day after the treatment, compared with the days before the study. A dosedependent increase in fecal output was observed at all time points. It has to be noted that during the period of 8 days rats gained 25\% body weight, an observation that mimics the known effects of ghrelin. After discontinuation of GRLN-R agonist, the weight returned to original values. Similarly to other GRLN-Rs agonists, the effects of GSK894281 were probably induced by stimulating receptors in the lumbo-sacral spinal cord.

\section{Ipamorelin}

Limited data is available on possible effects of ipamorelin in constipation-related disorders; however, there are in vivo studies and clinical trials assessing its capabilities in the treatment of POI.

Repetitive intravenous administration of ipamorelin $(0.1 \mathrm{mg} / \mathrm{kg}$ or $1 \mathrm{mg} / \mathrm{kg}$ ) accelerated colonic transit by shortening the time to the first bowel movement and significantly increased food intake and body weight in a rat model of POI. Single infusions of ipamorelin showed an increase in fecal pellet output. ${ }^{53}$

Recently, a multicenter double-blinded, placebo-controlled trial evaluated the safety of ipamorelin on patients with POI following abdominal surgery (ClinicalTrial.gov Identifier: NCT1280344). The treatment with ipamorelin was well tolerated but there were no significant differences in measurable motility parameter between placebo and treated groups. The most common treatment-associated adverse events were consistent with patients having undergone recent bowel surgery ie, nausea, vomiting, and dyspepsia, and may therefore not be associated with ipamorelin. However, the time to recovery of GI function was shorter in ipamorelin-treated group than in placebo. Helsinn Therapeutics, Inc is currently developing ipamorelin in a Phase $2 \mathrm{~b}$ clinical trial for the future treatment of postoperative bowel dysmotility (ClinicalTrial.gov Identifier: NCT00672074).

\section{Limitations and Directions for Future Research of Ghrelin Receptor Agonist}

The majority of studies mentioned in this paper support the notion that the small-molecule ghrelin and GRLN-R agonists may offer a well-integrated therapeutic option for the management of various hypomotility-related disorders, such as $\mathrm{CC}$ and POI (Table 2).

Several consistent results from both animal studies and clinical trials, provide strong evidence for powerful and sustainable effects of RM-131 in improving bowel function and increasing intestinal transit, without causing severe side effects. However, despite holding a great promise, further studies are still needed to fully establish the chronic effects of RM-131 on colonic motility.

As shown by the studies described herein, the effect of GRLN$\mathrm{R}$ agonists on lower GI transit was assessed mainly acutely in vitro and in vivo in the colon. Although most of the investigations followed well-designed protocols, and the results indicated pro-stimulatory actions of each agent on the intestines, none of available studies assessed the effects of a real long-term treatment. Importantly, 


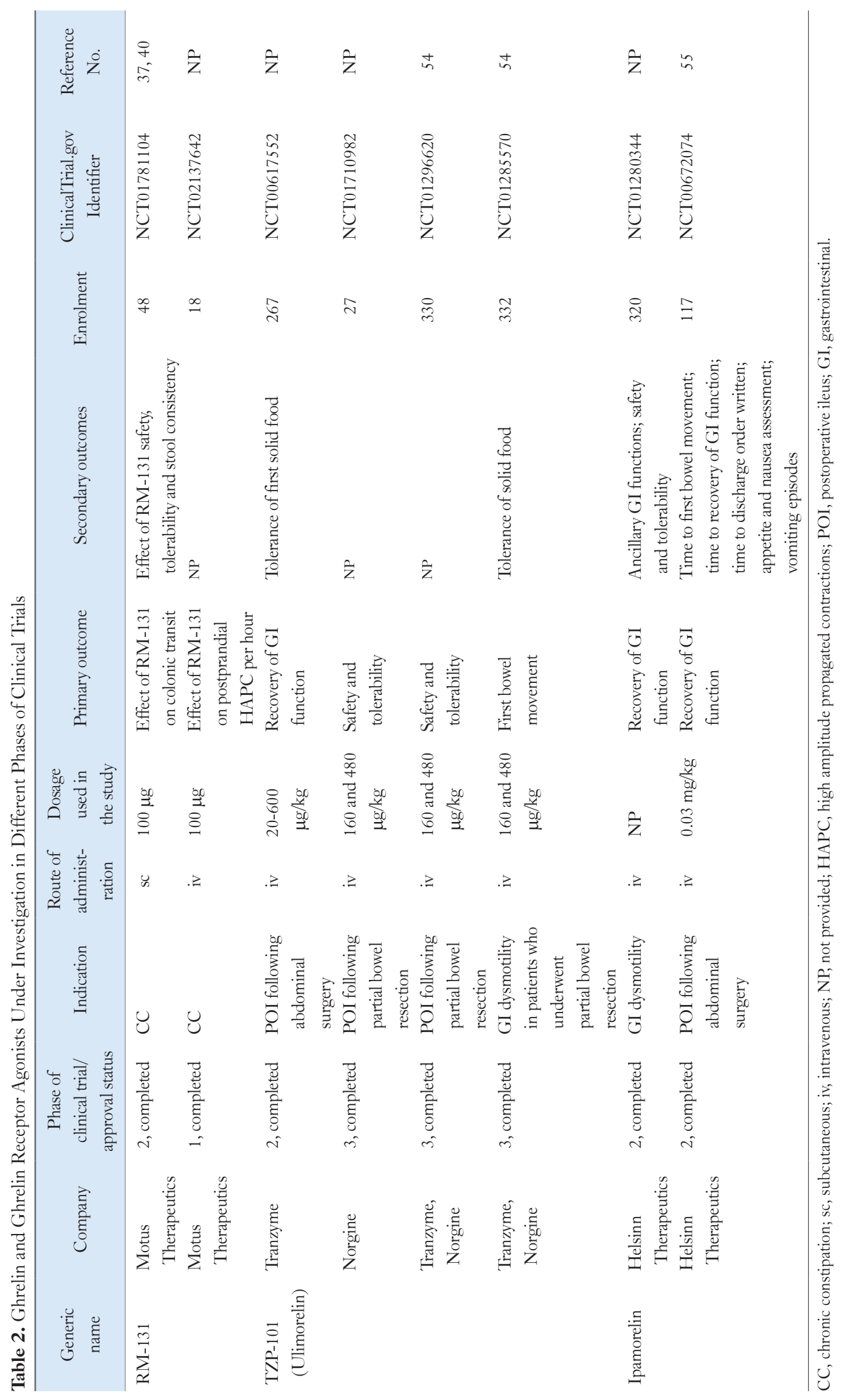


we should keep in mind that the tested agonists usually desensitize very easily, and thus may not sustain long enough to produce a desirable effect in a chronic mode of application.

In line, as mentioned before some GRLN-R agonists prompt colonic motility only after being administered intravenously or subcutaneously. If this beneficial effect of GRLN-R agonists may be maintained also after oral administration, these compounds may be useful in the future management of constipation or to ease cleansing the bowel before colonoscopy. At present, only GSK894281, given orally to rats, have elicited such effects. Presently, GSK894281 is the most promising compound that should be considered for further evaluation in clinical trials, especially being one of the very few that can cross the blood-brain barrier.

While improving the pharmacokinetic properties, it is advisable to consider not only the bioavailability of agents, but also the other effects of ghrelin and GRLN-Rs agonists on appetite, food intake and body weight, since these effects may limit the clinical long term usefulness. For example, EX-1314, which is currently under evaluation in preclinical in vivo studies, and also relamorelin and ipamorelin which have recently completed Phase 2 clinical trials, were associated with stimulation of GRLN-Rs in the appetite centers of the brain and increased appetite, thus their long-lasting use may be limited, especially when patient experience other comorbidities such as metabolic syndrome or type II diabetes. These aspects urgently need further attention, especially in the presently ongoing clinical trials.

In summary, considering the improvement in defecation patterns in animals and humans following administrations of GRLN$\mathrm{R}$ agonists, these agents may herald a new class of anti-constipation drugs. Additional clinical trials are necessary to further characterize and develop the promising clinical effects.

Financial support: This study was supported by the Medical University of Lodz (503/1-156-04/503-01 to Jakub Fichna and 502-03/1-156-04/502-14-299 to Paula Mosińska), National Science Center (2016/21/N/NZ5/01932 to Paula Mosińska), and the Deutsche Forschungsgemeinschaft (DFG) to Martin Storr.

\section{Conflicts of interest: None.}

Author contributions: Paula Mosińska, Hubert Zatorski, Martin Storr, and Jakub Fichna provided the overall concept and framework of the manuscript; Paula Mosińska researched and identified appropriate articles, and wrote the manuscript; Paula Mosińska, Hubert Zatorski, Martin Storr, and Jakub Fichna revised the manuscript; and all authors approved the final version of the manuscript.

\section{References}

1. Enck P, Leinert J, Smid M, Köhler T, Schwille-Kiuntke J. Prevalence of constipation in the German population - a representative survey (GECCO). United European Gastroenterol J 2016;4:429-437.

2. Chu H, Zhong L, Li H, Zhang X, Zhang J, Hou X. Epidemiology characteristics of constipation for general population, pediatric population, and elderly population in China. Gastroenterol Res Pract 2014;532734.

3. Papatheodoridis GV, Vlachogiannakos J, Karaitianos I, Karamanolis DG. A Greek survey of community prevalence and characteristics of constipation. Eur J Gastroenterol Hepatol 2010;22:354-360.

4. Rajput M, Saini SK. Prevalence of constipation among the general population: a community-based survey from India. Gastroenterol Nurs 2014;37:425-429.

5. Wald A, Mueller-Lissner S, Kamm MA, et al. Survey of laxative use by adults with self-defined constipation in South America and Asia: a comparison of six countries. Aliment Pharmacol Ther 2010;31:274-284.

6. Mosińska P, Salaga M, Fichna J. Novel investigational drugs for constipation-predominant irritable bowel syndrome: a review. Expert Opin Investig Drugs 2016;25:275-286.

7. Gray JR. What is chronic constipation? Definition and diagnosis. Can J Gastroenterol 2011;25(suppl B):7B-10B.

8. Emmanuel A, Quigley EM, Simrén M, et al. Factors affecting satisfaction with treatment in European women with chronic constipation: an internet survey. United European Gastroenterol J 2013;1:375-384.

9. Vengeliene $\mathrm{V}$. The role of ghrelin in drug and natural reward. Addict Biol 2013;18:897-900.

10. Stoyanova II. Ghrelin: a link between ageing, metabolism and neurodegenerative disorders. Neurobiol Dic 2014;72(Pt A):72-83.

11. Olszewski PK, Schiöth HB, Levine AS. Ghrelin in the CNS: from hunger to a rewarding and memorable meal? Brain Res Rev 2008;58:160170 .

12. Matuszyk A, Ceranowicz D, Warzecha Z, et al. The influence of ghrelin on the development of dextran sodium sulfate-induced colitis in rats. Biomed Res Int 2015;2015:718314.

13. Hosoda H, Kojima M, Kangawa K. Biological, physiological, and pharmacological aspects of ghrelin. J Pharmacol Sci 2006;100:398-410.

14. Eissa N, Ghia JE. Immunomodulatory effect of ghrelin in the intestinal mucosa. Neurogastroenterol Motil 2015;27:1519-1527.

15. Depoortere I. Targeting the ghrelin receptor to regulate food intake. Regul Pept 2009;156:13-23.

16. Maduzia D, Matuszyk A, Ceranowicz D, et al. The influence of pretreatment with ghrelin on the development of acetic-acid-induced colitis in rats. J Physiol Pharmacol 2015;66:875-885.

17. Stasi C, Milani S. Functions of ghrelin in brain, gut and liver. CNS Neurol Disord Drug Targets 2016;15:956-963.

18. Sivertsen B, Holliday N, Madsen AN, Holst B. Functionally biased signalling properties of 7TM receptors - opportunities for drug development for the ghrelin receptor. Br J Pharmacol 2013;170:1349-1362.

19. Avau B, Carbone F, Tack J, Depoortere I. Ghrelin signaling in the gut, 
its physiological properties, and therapeutic potential. Neurogastroenterol Motil 2013;25:720-732.

20. Nelson AD, Camilleri M, Acosta A, et al. Effects of ghrelin receptor agonist, relamorelin, on gastric motor functions and satiation in healthy volunteers. Neurogastroenterol Motil 2016;28:1705-1713.

21. Xu Y, Li Z, Yin Y, et al. Ghrelin inhibits the differentiation of T helper 17 cells through mTOR/STAT3 signaling pathway. PLoS One 2015;10:e0117081.

22. Mao Y, Tokudome T, Kishimoto I. Ghrelin and blood pressure regulation. Curr Hypertens Rep 2016;18:15.

23. Tokudome T, Kishimoto I, Miyazato M, Kangawa K. Ghrelin and the cardiovascular system. Front Horm Res 2014;43:125-133.

24. Orlova EG, Shirshev SV, Loginova OA. Leptin and ghrelin regulate dendritic cell maturation and dendritic cell induction of regulatory T-cells. Dokl Biol Sci 2015;462:171-174.

25. Muccioli G, Lorenzi T, Lorenzi M, et al. Beyond the metabolic role of ghrelin: a new player in the regulation of reproductive function. Peptides 2011;32:2514-2521.

26. Kojima M, Hosoda H, Date Y, Nakazato M, Matsuo H, Kangawa K. Ghrelin is a growth-hormone-releasing acylated peptide from stomach. Nature 1999;402:656-660.

27. Venkova K, Fraser G, Hoveyda HR, Greenwood-Van Meerveld B. Prokinetic effects of a new ghrelin receptor agonist TZP-101 in a rat model of postoperative ileus. Dig Dis Sci 2007;52:2241-2248.

28. Fraser GL, Venkova K, Hoveyda HR, Thomas H, GreenwoodVan Meerveld B. Effect of the ghrelin receptor agonist TZP-101 on colonic transit in a rat model of postoperative ileus. Eur J Pharmacol 2009;604:132-137.

29. Xu L, Depoortere I, Tomasetto C, et al. Evidence for the presence of motilin, ghrelin, and the motilin and ghrelin receptor in neurons of the myenteric plexus. Regul Pept 2005;124:119-125.

30. Sanger GJ, Furness JB. Ghrelin and motilin receptors as drug targets for gastrointestinal disorders. Nat Rev Gastroenterol Hepatol 2016;13:3848.

31. Fujino K, Inui A, Asakawa A, Kihara N, Fujimura M, Fujimiya M. Ghrelin induces fasted motor activity of the gastrointestinal tract in conscious fed rats. J Physiol 2003;550:227-240.

32. Fujitsuka N, Asakawa A, Amitani H, Fujimiya M, Inui A. Ghrelin and gastrointestinal movement. Methods Enzymol 2012;514:289-301.

33. Shimizu Y, Chang EC, Shafton AD, et al. Evidence that stimulation of ghrelin receptors in the spinal cord initiates propulsive activity in the colon of the rat. J Physiol 2006;576(Pt 1):329-338.

34. Ferens DM, Habgood MD, Saunders NR, et al. Stimulation of defecation in spinal cord-injured rats by a centrally acting ghrelin receptor agonist. Spinal Cord 2011;49:1036-1041.

35. Vestergaard ET, Hansen TK, Gormsen LC, et al. Constant intravenous ghrelin infusion in healthy young men: clinical pharmacokinetics and metabolic effects. Am J Physiol Endocrinol Metab 2007;292:E1829E1936.

36. Van der Ploeg L, Laken H, Sharma S, et al. Preclinical gastrointestinal prokinetic efficacy and endocrine effects of the ghrelin mimetic RM-131. Life Sci 2014;109:20-29.
37. Acosta A, Camilleri M, Kolar G, et al. Relamorelin relieves constipation and accelerates colonic transit in a phase 2, placebo-controlled, randomized trial. Clin Gastroenterol Hepatol 2015;13:2312-2319, e1.

38. Shin A, Camilleri M, Busciglio I, et al. Randomized controlled phase Ib study of ghrelin agonist, RM-131, in type 2 diabetic women with delayed gastric emptying pharmacokinetics and pharmacodynamics. Diabetes Care 2013;36:41-48.

39. Shin A, Camilleri M, Busciglio I, et al. The ghrelin agonist RM-131 accelerates gastric emptying of solids and reduces symptoms in patients with type 1 diabetes mellitus. Clin Gastroenterol Hepatol 2013;11:1453-1459, e4.

40. Acosta A, Camilleri M, Busciglio I, Boldingh A, Nelson AD, Burton D. Short-term effects of relamorelin on descending colon motility in chronic constipation: a randomized, controlled trial. Dig Dis Sci 2016;61:852860.

41. Acosta A, Kolar G, Iturrino J, et al. Sa2051 a phase II, randomized, double-blind, placebo-controlled, multiple-dose, parallel-group study to evaluate the efficacy, safety, and pharmacodynamics of RM-131 in patients with chronic constipation. Gastroenterology 2014;146:S-364

42. De Schryver AM, Andriesse GI, Samsom M, Smout AJ, Gooszen HG, Akkermans LM. The effects of the specific $5 \mathrm{HT}_{4}$ receptor agonist, prucalopride, on colonic motility in healthy volunteers. Aliment Pharmacol Ther 2002;16:603-612.

43. Leelakusolvong S, Bharucha AE, Sarr MG, Hammond PI, Brimijoin $\mathrm{S}$, Phillips SF. Effect of extrinsic denervation on muscarinic neurotransmission in the canine ileocolonic region. Neurogastroenterol Motil 2003;15:173-186.

44. Bampton PA, Dinning PG, Kennedy ML, Lubowski DZ, Cook IJ. The proximal colonic motor response to rectal mechanical and chemical stimulation. Am J Physiol Gastrointest Liver Physiol 2002;282:G443G449.

45. Sha L, Van der Ploeg LH, Szurszewski JH. Effect of RM-131 on circular smooth muscle cells in human and mouse colon and on colonic intraluminal pressure in conscious mice. Gastroenterology 2014;146:S363.

46. Shafton AD, Sanger GJ, Witherington J, et al. Oral administration of a centrally acting ghrelin receptor agonist to conscious rats triggers defecation. Neurogastroenterol Motil 2009;21:71-77.

47. Pustovit RV, Callaghan B, Kosari S, et al. The mechanism of enhanced defecation caused by the ghrelin receptor agonist, ulimorelin. Neurogastroenterol Motil 2014;26:264-271.

48. Pustovit R V., Furness JB, Rivera LR. A ghrelin receptor agonist is an effective colokinetic in rats with diet-induced constipation. Neurogastroenterol Motil 2015;27:610-617.

49. Ellis AG, Zeglinski PT, Brown DJ, Frauman AG, Millaed M, Furness JB. Pharmacokinetics of the ghrelin agonist capromorelin in a single ascending dose phase-I safety trial in spinal cord-injured and able-bodied volunteers. Spinal Cord 2015;53:103-108.

50. Charoenthongtrakul S, Giuliana D, Longo KA, et al. Enhanced gastrointestinal motility with orally active ghrelin receptor agonists. J Pharmacol Exp Ther 2009;329:1178-1186.

51. Callaghan B, Kosari S, Pustovit RV, et al. Hypotensive effects of ghrelin 
receptor agonists mediated through a novel receptor. Br J Pharmacol 2014;171:1275-1286.

52. Bassil AK, Dass NB, Murray CD, Muir A, Sanger GJ. Prokineticin-2, motilin, ghrelin and metoclopramide: prokinetic utility in mouse stomach and colon. Eur J Pharmacol 2005;524:138-144.

53. Venkova K, Mann W, Nelson R, Greenwood-Van Meerveld B. Efficacy of ipamorelin, a novel ghrelin mimetic, in a rodent model of postoperative ileus. J Pharmacol Exp Ther 2009;329:1110-1116.
54. Shaw M, Pediconi C, McVey D, et al. Safety and efficacy of ulimorelin administered postoperatively to accelerate recovery of gastrointestinal motility following partial bowel resection: results of two randomized, placebo-controlled phase 3 trials. Dis Colon Rectum 2013;56:888-897.

55. Beck DE, Sweeney WB, McCarter MD; Ipamorelin 201 Study Group. Prospective, randomized, controlled, proof-of-concept study of the ghrelin mimetic ipamorelin for the management of postoperative ileus in bowel resection patients. Int J Colorectal Dis 2014;29:1527-1534. 